\title{
A TRAVESSIA DE SÃO PAULO A NADO (1924-1944) E O PROCESSO DE ESPORTIVIZAÇÃO AQUÁTICA PAULISTANA
}

\author{
Title: The swim across São Paulo (1924-1944) and the sportization of \\ aquatic practices in the city
}

\author{
Daniele Cristina Carqueijeiro de Medeiros \\ Evelise Amgarten Quitzau ${ }^{2}$ \\ Marcelo Moraes e Silva ${ }^{3}$
}

\begin{abstract}
RESUMO
Neste artigo analisamos as transformações realizadas na "Travessia de São Paulo a Nado", maior prova aquática realizada no rio Tietê, desde sua primeira edição, em 1924, até a última, em 1944. O objetivo foi evidenciar, a partir dessa competição, as transformações em curso nas práticas aquáticas realizadas no rio, que deixavam, pouco a pouco, de serem mero divertimento para se afinarem às lógicas do esporte moderno. As fontes utilizadas para o trabalho foram os jornais A Gazeta e Correio Paulistano. Na competição foram ajustadas regras, inseridos árbitros, realocadas as saídas, entre diversos outros aspectos. A combinação desses fatores adequou o evento às demandas do esporte moderno, embora o rio enquanto elemento da natureza proporcionasse incertezas acerca dos recordes e das marcas a serem obtidas.
\end{abstract}

Palavras-chave: História do Esporte; Natação; Cultura Física.

\begin{abstract}
In this article we analyze the changes that occurred in the "Swimming across São Paulo", the largest aquatic event held in the Tietê river, since its first edition in 1924, until the last one, in 1944. The aim was to highlight, from this competition the ongoing transformations in the aquatic practices carried out in the river, wich were, little by little, no longer mere fun to be in tune with the logics of modern sports. The sources used for this article were the newspapers A Gazeta and Correio Paulistano. In the competition rules were adjusted referees were inserted, exits were relocated, among several other aspects. The combination of these factors adjusted the event to the requirements of modern sports, although the river, as an element of nature, provided uncertainties about the records and the marks to be obtained.
\end{abstract}

Keywords: History of Sport; Swimming; Physical Culture.

1 Doutoranda em Educação - UNICAMP. E-mail: danieli_ccm@hotmail.com.

2 Doutora em Educação - UNICAMP. Docente do curso de Licenciatura em Educação Física e do Programa de Mestrado em Educação Física do Instituto Superior de Educación Física, da Universidad de la República, Uruguai, e é pesquisadora Nível 1 do Sistema Nacional de Investigadores da Agencia Nacional de Investigación e Innovación (SNI/ANII). E-mail: eveliseaq@ yahoo.com.br. ORCID: http://orcid.org/0000-0001-9789-6488.

3 Doutor em Educação - UNICAMP. Professor do Departamento e do Programa de Pós-Graduação em Educação Física -e do Programa de Pós-Graduação em Educação - UFPR. E-mail: moraes_marc@yahoo.com.br. ORCID: http://orcid.org/00000001-6640-7952. 


\section{Introdução}

Os rios paulistanos figuraram na imaginação da população urbana ora como um lindo espetáculo da natureza, ora como perigo iminente àqueles que ousaram desafiá-los. Jorge (2006) e Sant'Anna (2007), argumentam que, no século XIX, com o desenvolvimento das pesquisas sobre a higiene e sobre a teoria microbiana, as águas do Tietê e seus afluentes foram interditadas, tanto por médicos e sanitaristas que temiam os perigos provenientes das águas, quanto pela segurança pública, que procurava evitar tragédias e afogamentos.

Havia, por outro lado, um uso crescente dos rios nesse período como locais de trabalho, meio de transporte, fornecimento de alimentação (JORGE, 2006; 2011; SANT'ANNA 2007; GOUVEIA, 2016). Os rios eram parte constituinte da cidade, ainda que remetessem a uma natureza rude e pouco controlável pelas mãos humanas. Havia certo descompasso entre a fúria das águas e as possibilidades de contê-las através da engenharia moderna, o que tornava os rios exóticos em meio ao cenário urbano que se desenrolava.

Vigarello (2019), ao analisar o contexto francês, indica que foi preciso um grande deslocamento de sensibilidades para que os rios fossem reabilitados para o uso humano. $\mathrm{O}$ historiador indica que desafiar as águas e refrescar os corpos passaram, pouco a pouco, a serem práticas possíveis nas águas fluviais, inclusive passando a ser vistas como uma forma de revigorar o corpo. Rauch (1995) salienta que um entendimento carregado de novas relações para com a natureza foi o que permitiu que os rios fossem admirados, contemplados e utilizados nesse cenário.

Por sua vez, Vigarello e Holt (2005) e Vigarello (2018a; 2019) argumentam que, na busca do revigoramento do corpo que a vida citadina exigia, uma série de pedagogias corporais emergiram no contexto europeu a partir do fim do século XVIII. Rauch (1995) e Vigarello (2019) indicam que todas essas pedagogias passavam a valorizar os banhos nos rios como importante recurso de revitalização e higiene. Consideradas moralmente úteis, essas pedagogias, conforme evidencia Vigarello (2018a), poderiam proteger os indivíduos, visto que passavam a ser consideradas importantes aliadas da higiene e da saúde, marca central do projeto urbano que se consolidava no mundo ocidental.

Terret $(1994 ; 1998)$ também segue essa linha argumentativa ao explorar o nascimento, a difusão e a institucionalização da natação na França a partir da segunda metade do século XIX. O autor salienta que foram essas novas sensibilidades e pedagogias que possibilitaram a utilização das águas dos rios como espaços de desafios aquáticos, que posteriormente deram origem a esportes como a natação.

Os desafios aquáticos inauguraram novos usos possíveis dos rios, fazendo emergir no contexto europeu da segunda metade do século XIX práticas como a natação e o remo (TERRET, 1994; 1998; VIVIER, 1998; 1999; PELAYO, 2010; MACHEMEHL, 2011). Existem evidências de que, na virada para o século XX, tais práticas também já eram realizadas no Brasil, como por exemplo, as notas encontradas nos jornais que relatavam desafios de pulos e de nado nas águas do Tietê (NATAÇÃO, 1898). Pouco tempo depois, a criação de clubes de regatas nas margens do Tietê e Pinheiros, sendo o primeiro deles o clube Esperia, em 1899, colaborou para o surgimento de inúmeras outras práticas da cultura física nos rios paulistanos, especialmente as mais esportivizadas, como a natação e o remo.

Nesse sentido, o objetivo desse artigo foi analisar as transformações em curso nas práticas da cultura física realizadas nos rios paulistanos, que paulatinamente deixavam de 
serem mero divertimento para adentrarem nas lógicas do esporte moderno. Para esta análise, observaremos mais especificamente a Travessia de São Paulo a Nado, prova realizada no rio Tietê entre 1924 e 1928 e, posteriormente, entre 1932 e 1944.

Essa competição foi escolhida para representar tais transformações pois foi, à época, a prova mais importante da natação paulistana, e chegou a conjugar mais de 1500 nadadores em uma de suas dezoito edições. Neste evento, diversas foram as transformações ocorridas ao longo dos anos que acabaram por aproximá-la de uma prática mais esportivizada, ou seja, com regras mais bem definidas ${ }^{4}$. Foi também nesse espaço que surgiram importantes atletas como João Havelange, Maria Lenk, Sieglinde Lenk e Scylla Venâncio, que posteriormente participaram e representaram o Brasil nos Jogos Olímpicos (NICOLINI, 2001; DEVIDE; VOTRE, 2012).

A pesquisa, de cunho historiográfico, teve como fontes as edições dos jornais Correio Paulistano e A Gazeta publicadas no período recortado. Os jornais constituíram-se, ao longo do século XX no Brasil, em importantes fontes para pesquisas históricas. Nas investigações sobre São Paulo, Cruz (2000) ressalta que o movimento de crescimento e circulação de materiais impressos acompanhou o ritmo de desenvolvimento da cidade. Logo, os jornais e outros periódicos impressos foram responsáveis por divulgar novas imagens da cidade, que coincidiam com a modernidade que se pretendia estampar. Os esportes e outras práticas da cultura física se fizeram presentes nos jornais como símbolo dessa modernidade. Exemplo disso são os jornais Correio Paulistano e A Gazeta, que já nos primeiros anos do século XX inauguraram em suas páginas uma seção chamada rowing, dedicada a narrar apenas fatos ligados às práticas aquáticas.

O jornal $A$ Gazeta teve importante participação na difusão de um "modo de ser paulistano", principalmente pela difusão do lema que São Paulo "não podia parar". Assim, retratar os esportes auxiliava a idealização de que a cidade emanava vigor físico, competitividade, competência e organização (TOLEDO, 2012). O seu modo de elaborar um jornalismo esportivo também foi bastante inovador. As páginas dedicadas às notícias esportivas sempre tiveram a intenção de ganhar feição popular, e suas narrativas, associadas à publicação de fotografias, reiteravam esse ideal a todo tempo (TOLEDO, 2012). Com papel importante na divulgação do futebol paulistano e também de outros esportes, o jornal, sob o comando de Casper Líbero 5 , também foi responsável por promover grandes eventos esportivos populares na cidade, como a Travessia de São Paulo a Nado, a prova ciclística 9 de julho, criada em 1933, e a prova de corrida de rua São Silvestre, cuja primeira edição ocorreu em 1925.

O jornal Correio Paulistano foi um dos maiores do Brasil e o primeiro a ser publicado diariamente na cidade de São Paulo. Criado por Joaquim Roberto de Azevedo Marques em 1854, o periódico circulou por mais de cem anos, com um total de 33.882 edições. Inicialmente, não havia relações evidentes do jornal com partidos políticos. Entretanto, a partir de 1890, ele se associou ao Partido Republicano Paulista (PRP) e tornou-se seu órgão oficial de divulgação; isso significava uma defesa dos princípios liberais, mas sem o abandono do conservadorismo

4 Segundo apontam Elias e Dunning (1992) o fenômeno da esportivização foi o processo pelo qual jogos, passatempos e divertimentos populares foram se transformando em práticas institucionalizadas e regradas.

5 Casper Líbero, advogado e jornalista, adquiriu A Gazeta ainda em 1918, e modernizou seu modo de produção, diagramação e impressão. Sua trajetória no jornalismo foi descrita por Toledo (2012) e Jayo (2003) como a de um "malabarista" político, ou seja, a de um jornalista que manobrava suas relações com o poder e a política de forma a concretizar o ideal de viabilizar seu projeto jornalístico. 
proposto pelas elites (THALASSA, 2007). De acordo com Gois Júnior (2017), o fato de o jornal se autoproclamar porta-voz de uma visão política liberal e, dessa forma, representar uma identidade paulista, torna-o uma fonte relevante para a análise do projeto moderno proposto à cidade, em que se incluíam, certamente, a educação física e o esporte.

\section{Uma cultura física para São Paulo}

As transformações frementes que aturdiam São Paulo, ligadas à sua urbanização, alteravam não só o cenário urbano e o uso dos rios, mas uma infinidade de modos e costumes, que precisavam se adequar à nova cidade que se formava (SEVCENKO, 2000). Logo, era urgente que uma cultura física se impusesse aos seus habitantes. Nesse sentido, nos valemos nesse artigo do conceito de cultura física evidenciado por Kirk (1999, 2008) e Scharagrodsky (2014). Para esses autores, a cultura física é um terreno em que atores, agentes e grupos sociais colocaram em circulação um conjunto heterogêneo de significados voltados ao corpo. Assim, a conceituação é uma fonte de produção e reprodução do discurso corporal que tem como intenção legitimar os significados atrelados ao corpo humano.

No Brasil, mais especificamente em Curitiba, Moraes e Silva (2011, 2015), Moraes e Silva e Quitzau (2018) e Moraes e Silva, Quitzau e Soares (2018) analisaram os significados atrelados à cultura física ${ }^{6}$. Para os autores, seu despertar no Brasil tece relações com os processos de modernização, seguindo uma nova ordem urbana que se instalava no país. Foram encontradas distintas intenções de regulamentação e direcionamento das práticas realizadas na cidade, que eram promovidas por meio de discursos médicos, científicos, higiênicos e pedagógicos.

Isso posto, era patente que, numa São Paulo que também procurava se modernizar, novos significados deveriam ser atrelados ao corpo, principalmente relacionados à moral esportiva que despontava na cidade. Era necessário, portanto, inserir diretrizes morais e práticas às atividades realizadas, para que elas adentrassem o escopo adequado da cultura física pretendida.

Os clubes náuticos da cidade tinham como objetivo bem estabelecido organizar as competências e regras necessárias às "boas práticas" esportivas. Isso significava incutir aos associados noções sobre como ser esportivo, sobre os benefícios morais e higiênicos das práticas esportivas, aspectos relativos ao comportamento adequado durante uma disputa tanto por parte dos atletas quanto dos torcedores - e sobre quais eram as práticas bem aceitas pelos clubes.

Vigarello (2018b), ao explorar historicamente o conceito de cultura física, indica que, com a emergência do esporte no fim do século XIX, o corpo passava a ser uma imensa máquina suscetível a diversas modulações possibilitadas pelo fenômeno esportivo. Para Vigarello (2002; 2018b), Bourdieu (2003) e Terret (2019), a prática esportiva precisava ser divulgada sob a égide de preceitos morais para que os objetivos de mobilização da juventude por meio de um projeto de viés educativo pudessem obter êxito. Logo, os clubes paulistanos

6 No que concerne ao conceito de cultura física e uma historiografia das práticas corporais no Brasil indica-se, para além dos trabalhos sobre a cidade de Curitiba, os artigos de Furtado, Quitzau e Moraes e Silva (2018), sobre Blumenau e o de Montenegro e Soares (2019) relativo a Fortaleza. 
divulgavam com frequência seus "manuais de boas práticas", que continham elementos como: o incentivo ao amadorismo (ORIENTAÇÃO...1940), a prática do esporte através do fair play (O QUE É...1936), o treinamento e a obstinação nas competições mesmo diante das derrotas (O VERDADEIRO...1932). Assim, é possível afirmar que os clubes esportivos se muniam dos discursos correntes a respeito do benefício do esporte e da prática de exercícios e, dessa forma, produziam sua própria definição de cultura física.

Essa cultura física, ao longo dos anos, tornou-se cada vez mais esportivizada. De acordo com Vigarello e Holt (2005), Kirk (2008), Vigarello (1995; 2008; 2018a; 2018b) e Terret (2019), ao longo do século XX houve uma mudança muito sensível de paradigmas, que foram das ginásticas aos esportes. Essa mudança levou décadas para ser completamente produzida e difundida, já que novas bases morais e filosóficas precisavam ser construídas.

Com relação à cultura física paulistana não foi diferente, e foi possível notar que, ao longo das primeiras décadas do século XX, uma esportivização das práticas aquáticas estava em pleno curso na cidade de São Paulo. Os eventos realizados no início do século pelos clubes de regatas ainda tratavam de forma difusa a ideia do esporte, de maneira que as atividades realizadas eram bastante distintas, como remo, natação, competição de pulos e até tiro aos pombos (CLUB..., 1904).

Com o tempo, as competições começaram a ser anotadas de outra forma nos jornais, com mais riqueza de detalhes, tendo a premiação divulgada e as categorias descritas:

As 2 horas e meia da tarde - Match em yoles gigs a 4 remos -2.000 metros, contra a correnteza - Premio: medalha de prata aos vencedores [...] As 3 e meia horas da tarde - Match em yoles gigs e dois remos - 1.000 metros - medalha de bronze aos vencedores (ROWING, 1905, p. 5)

Mesmo que certas especificações começassem a aparecer na divulgação dos eventos náuticos, os primeiros festivais possuíam muito pouco das definições do esporte moderno, como a especificidade das regras, a marcação do tempo, a seleção de árbitros (GUTTMANN, 2004; LOUDCHER, 2008). A emergência do esporte moderno proporcionou uma profunda transformação que passou do "livre jogar" - a forma como os jogos eram realizados anteriormente, com regras pouco claras - para práticas com regras universais e pré-determinadas (ELIAS; DUNNING, 2002; VIGARELLO, 2008; 2018b; TERRET, 2019). Assim, o aprimoramento das regras - e, consequentemente, das práticas - foi um dos aspectos determinantes para a sua formação, como afirmam Elias e Dunning (1992), Bourdieu (2003), Vigarello (2002; 2018b), Guttmann (2004) e Terret (2019).

A criação de federações, confederações e ligas serviu aos intentos dessa racionalização e burocratização das práticas, que se tornava cada vez mais universal (GUTTMANN, 2004; LOUDCHER, 2008; VIGARELLO, 2018b; TERRET, 2019). É possível afirmar que o surgimento destes elementos regulamentadores transformou o modo como os clubes realizavam seus festivais, aproximando-os muito mais das práticas constituídas no arcabouço do esporte moderno. Não é anódino pensar, entretanto, que essas transformações se deram em momentos distintos, de forma não homogênea e que enfrentaram resistências.

As décadas analisadas nesse artigo conjugam um momento em que as práticas aquáticas na cidade de São Paulo ansiavam, particularmente através dos clubes e federações, por uma transformação, em que os elementos constituintes dos esportes se tornassem parte indissociável 
das atividades realizadas, fato que não deixaria dúvidas sobre o caráter esportivo das atividades clubísticas.

Esse conjunto de fatores acabou por influenciar também as competições chamadas "travessias", em que determinado trecho do rio era atravessado a nado pelos participantes. Diversas dessas provas ${ }^{7}$ existiram em São Paulo nas primeiras décadas do século XX, mas tomaremos como objeto de análise somente a mais importante delas: a Travessia de São Paulo a Nado.

\section{As transformações na travessia de São Paulo a nado}

A Travessia de São Paulo a Nado, prova mais importante da natação paulista nas primeiras décadas do século XX, foi instituída em 1924 pelo jornal São Paulo Esportivo com o apoio da Federação Paulista das Sociedades do Remo (FPSR) e durou até 1928, momento do fechamento do jornal. Em 1932 a prova foi restabelecida, então sob o patrocínio do jornal A Gazeta e, nessa segunda fase, a perdurou até 1944, quando o evento deixou de existir. (NICOLINI, 2001).

Ao longo da sua existência, muitas mudanças ocorreram, seja no trajeto, nas regras ou premiações. Certamente, tais transformações tentaram adequar a prova às novas imposições esportivas, o que a aproximaria das práticas ligadas à natação em sua forma internacionalmente institucionalizada ${ }^{8}$. Podemos considerar que essas metamorfoses foram cruciais para a manutenção da competição ao longo dos anos.

As provas conhecidas como travessias eram famosas em outras localidades no início da década de $1920^{9}$, e a imprensa esportiva paulistana começava a se perguntar sobre o momento em que evento semelhante seria realizado em São Paulo. O jornal A Gazeta, em 1924, noticiouse o "burburinho" a respeito de uma prova de travessia que ocorreria no rio Tietê desde a Penha até a Ponte Grande. Havia, como pano de fundo da notícia, uma crítica à falta de organização, até o momento, de uma competição como essa:

Será possível que só na terra de Tibiriça, não se consiga uma prova natatória de vulto? Achamos que com bôa vontade, e alguns treinos preparatorios, não faltará ahí um nucleo de destemidos bandeirantes aptos a tentar a descida do velho rio das monções, creando em S. Paulo uma das bellas competições de aquatica (E A TRAVESSIA...1924, p.4).

Uma primeira iniciativa nesse sentido foi realizada por René Feraudy e Rogerio de Mello, nadadores cariocas filiados ao clube Vasco da Gama, da cidade do Rio de Janeiro, que

7 Além da Travessia de São Paulo a nado, outras travessias também foram realizadas no rio Tietê nas primeiras décadas do século XX, como a "Travessia de Penha a Nado", "Prova Johnny Weissmuller" e "Prova Walter Ceccon".

8 Machemehl (2011), ao analisar a cidade de Rouen na França, numa temporalidade semelhante, aponta para movimentações muito parecidas nas práticas náuticas ocorridas na cidade localizada na Normandia.

9 Neste mesmo período encontramos, na América do Sul, a primeira travessia a nado do Rio da Prata, realizada com êxito pela nadadora Lilian Harrison no ano de 1923 (SCHARAGRODSKY, 2019). Na Europa, por outro lado, a travessia do Canal da Mancha, um dos mais tradicionais desafios em águas abertas, já era realizada desde 1875 (TERRET, 1995) 
pretendiam realizar uma travessia em São Paulo a nado. A prova, que teria um percurso de mais de trinta quilômetros, entre o Porto de Guarulhos e a Ponte Grande era, para o jornal, um grande incentivo aos nadadores da cidade, que deveriam, a partir do exemplo "desde já se entregar aos treinos preparatórios" (UMA IMPORTANTE....1924, p.4)

Essas iniciativas podem ser consideradas precursoras daquilo que seria a Travessia. Dentro de poucos dias, enfim, anunciou-se que o evento seria realizado ainda em 1924. O jornal São Paulo Esportivo resolvera patrocinar a competição e instituiu prêmios a todas as colocações, o que tornava cada vez mais iminente a realização da prova. Era preciso, no entanto, determinar as regras da disputa. Para isso, o jornal convocou uma reunião com as agremiações náuticas interessadas em participar da prova, para que tais questões pudessem ser estabelecidas (A TRAVESSIA...1924a).

Em novembro do mesmo ano foram abertas as inscrições para os participantes. Nesse primeiro ano, foram aceitas inscrições apenas dos nadadores afiliados à FPSR, ou de atletas que fossem representar clubes que pertencessem à Federação. A premiação foi estabelecida até o quinto colocado na categoria masculina e até terceira posição na feminina. Todos os competidores homens que terminassem a prova até vinte minutos após o primeiro colocado também receberiam premiação, assim como todas as nadadoras que finalizassem o percurso. A data da prova não foi escolhida de forma anódina:

Foi escolhida a data de 28 de dezembro por ser a época mais propicia devido a cheia do Tietê, bem como por estar afastada das provas da Federação Paulista e das nauticas dos clubes filiados, dando tempo assim de sobejo para alguns treinos mais, dos concorrentes. Além disso, sera o ultimo domingo de 1924, o que dá á competição um caracter extraordinario de despedida esportiva da temporada (A TRAVESSIA...1924b, p.3)

A largada seria realizada com todos os competidores ao mesmo tempo, e duas classificações seriam fornecidas, uma para os homens e outra para as mulheres. A comissão de arbitragem da prova foi constituída por 1 árbitro geral, 1 juiz de saída, 3 juízes de chegada e 1 juiz de percurso para cada três concorrentes (A TRAVESSIA...1924b, p.6). Apesar da pequena quantidade de informações divulgadas sobre a primeira edição da travessia nos dois jornais analisados (apenas três reportagens, que mencionavam os aspectos gerais da organização), o número de participantes (36 inscritos) e a divulgação do evento foram considerados satisfatórios, o que deixava subentendido que a prova continuaria a ser realizada.

Para a Travessia de 1925, uma maior importância foi dada ao regulamento: duas semanas antes da realização da prova, ele foi publicado na edição 5954 d'A Gazeta (1925). É possível perceber algumas diferenças em relação à primeira disputa. Na segunda edição, cada clube participante deveria enviar à prova um barco de socorro, elemento não anunciado em 1924; os juízes deveriam pertencer ao quadro da FPSR e, na chegada, foram adicionados cinco cronometristas; as medalhas foram entregues aos participantes que chegaram até quinze minutos depois do primeiro colocado geral.

As fontes fornecem vestígios de que o tempo era uma questão que passava a ser fundamental para o estabelecimento da prova. Isso indica que seus idealizadores buscavam inserir a competição nas lógicas do esporte moderno, tanto quando pensado em uma perspectiva macro - calendários, por exemplo - como em uma esfera micro - o tempo nos próprios jogos (VIGARELLO, 1995; 2002; 2008). Se por um lado os jogos eram anteriormente 
ligados a festivais e rituais, a secularização e o advento do esporte moderno implicaram numa independência do calendário esportivo em relação às outras práticas do cotidiano.

Sobre a temática do calendário, o historiador francês Vigarello (2002, p.76 - tradução livre) faz os seguintes apontamentos:

[a transformação do calendário] [...] facilitou a invenção de períodos de preparação, por exemplo, sendo dominantes os momentos de aprendizagem e as fases de aperfeiçoamento. O calendário não distribui apenas os atos do jogo, distribui também os atos que o preparam. Ele permite a alternância dos treinamentos e dos reencontros. Ele marca o ritmo do tempo que separa as provas.

Quanto mais o esporte se burocratizava e racionalizava, mais seus tempos e calendários se tornavam independentes (VIGARELLO, 1995; 2002). O tempo é fator crucial às competições aqui analisadas, pois é a partir dele que os esportes de marca, como a natação e o remo, determinam os vencedores das disputas (TERRET, 1994; 1998; VIVIER, 1999; PELAYO, 2010; MACHEMEHL, 2011). Ele se torna um imperativo da quantificação e, principalmente, da determinação do recorde, símbolo máximo deste processo de racionalização capitaneada pelo esporte moderno (GUTTMANN, 2004; LOUDCHER, 2008; VIGARELLO, 1995; 2002; 2008; 2018b), que permite ao competidor manter seu nome por um período um pouco mais longo no topo dos rankings. Vigarello (1995; 2002; 2008; 2018a) salienta que foram as cifras tempo e espaço que possibilitaram a criação de uma pedagogia que instalava a performance como um índice de aperfeiçoamento corporal.

Vigarello (1995; 2008; 2018a) afirma que a cifra era uma nova maneira de contar temporalmente um exercício, uma forma de comparar durações, de compreender a velocidade e valorizar a rapidez. O historiador francês argumenta que essa celeridade impunha um espetáculo. O relógio havia se tornado para o atleta de certas modalidades um ponto de referência para os seus gestos, pois os corpos estavam agora arrebatados pela velocidade. A cronometragem dos competidores era, portanto, um fator de suma importância para o sucesso de qualquer competição e por isso não é de estranhar que tais cuidados fossem instituídos desde a segunda edição da prova paulistana.

Porém, um dado bastante impreciso nos primeiros anos de realização da Travessia foi sua distância total. Embora todas as provas tenham sido realizadas com o mesmo ponto de partida e chegada - a Ponte da Vila Maria e o clube Esperia, localizado na Ponte Grande a quilometragem a ser percorrida pelos nadadores foi divulgada de forma distinta ao longo dos anos. Em 1926, anunciou-se que o percurso teria 6 mil metros (A III...,1926). Em 1927, a distância anunciada foi outra: 6,7 km (A IV...,1927). Em 1932, com a retomada da prova após quatro anos de não realização, anunciou-se que o caminho a ser percorrido teria 7200 metros. Apenas em 1933, após retificação da organização da prova, instituiu-se 5350 metros, que no ano seguinte foi mudado para 5500 metros e tornou-se o percurso oficial até a última ocorrência da prova, em 1944 (NICOLINI, 2001). Torna-se importante conceber que, com distâncias diferentes, os recordes anotados na prova não teriam a validade de comparação entre um ano e outro, fator bastante importante para a determinação dos maiores velocistas na prova.

Em 1927, impulsionadas pela maior quantidade de competidores, foram organizadas três largadas diferentes. Na primeira competiriam até três atletas de cada clube, que seriam os concorrentes dos prêmios especiais distribuídos na prova. Na segunda saída, os demais 
competidores disputariam uma classificação marcada pelo tempo, do sexto colocado em diante. A terceira saída era destinada às competidoras da classe feminina. $\mathrm{O}$ juiz geral da prova foi indicado de antemão e anunciado nos jornais, e as agremiações náuticas seriam responsáveis por indicar, cada uma, seis dos demais árbitros da prova. (A IV...,1927).

Além disso, outros aprimoramentos foram sendo realizados pelos organizadores da prova. Um sistema de reconhecimento dos concorrentes começou a ser implantado no ano de 1927: o uso de gorros numerados: "Todo o concorrente é obrigado a ter no gorro o numero correspondente, conservando-o até a chegada, sob pena de desclassificação." (IV TRAVESSIA...1927, p.8). O mecanismo permitia que os concorrentes fossem facilmente identificados durante todo o percurso facilitando a anotação de faltas e possíveis punições.

As competições, quanto mais disputadas, mais se inseriam num dispositivo esportivo (VIGARELLO, 1995; 2002; 2018b; MORAES E SILVA, 2011), vendo-se rodeadas de regras; estas surgiam quando havia a necessidade de exclusão de determinada conduta. É provável que, nos primeiros anos de disputa, tenha sido complexo acompanhar todos os nadadores e prever todas as suas atitudes ao longo da prova. O gorro, como um material bastante específico implantado para a regulamentação da prática, permitiu um controle maior na disputa e mesmo na conduta dos atletas participantes.

É possível perceber que, com o passar das edições, uma preocupação maior com a regulamentação foi se instituindo. Além do aumento no número de juízes atuantes na competição, inserção de cronometristas e preocupação com a identificação dos participantes, as regras foram ganhando cada vez mais destaque, a ponto de os jornais paulistanos publicarem notas enfatizando o papel da arbitragem nas disputas. Em 1928, a dois dias da realização da competição, um artigo foi destinado especialmente aos juízes, detalhando suas obrigações na Travessia:

\section{DISPOSIÇÕES DO ARBITRO}

São estas as disposições tomadas pelo arbitro:

$[\ldots]$

Fará a chamada o chefe das sahidas, que estará em logar marcado com flamula branca;

Os juizes de percurso deverão apresentar ao ser chefe (logar marcado com flamula vermelha) ás 14,20 horas;

Os chronometristas deverão apresentar-se ao seu chefe no logar tambem marcado com flamula vermelha;

[Sera punida] Qualqur desobediência, por parte de juizes, concorrentes ou associados de clubs federados, durante o desenrolar da prova;

Os juizes de percurso, chegando na Ponte Grande, deverão encostar seus barcos na margem direito do rio e perto da chegada entrarem no canal no Club Esperia.

[...] (DISPOSIÇÕES...1928, p.12)

Entretanto, o aumento na fiscalização não impediu que problemas ocorressem durante a realização da prova. Em 29 de dezembro, o jornal Correio Paulistano publicou uma nota que informava um pedido de inquérito feito pelo clube Esperia à FPSR para apuração dos resultados de 1928, a fim de "[...] evitar qualquer interpretação erronea ou malevola" (A TRAVESSIA..., 1928, p.9).

Apesar do aparente sucesso da prova, que cada vez recebia mais atenção da imprensa, ela deixou de ser realizada entre 1929 e 1931. O motivo evidente foi o fechamento do jornal 
São Paulo Esportivo, o principal patrocinador da competição: "Desapparecido o 'São Paulo Sportivo' a prova deixou de existir e o esporte nautico perdeu a sua mais popular manifestação de propaganda" (“A GAZETA”...,1932, p.9).

Em janeiro de 1932, A Gazeta anunciou que, associada à FPSR, iria fazer ressurgir a prova, que não havia sido disputada nos três últimos anos. De acordo com o jornal, a Travessia, que já havia se tornado tradicional, tinha sido, desde sua primeira aparição, um sucesso "[...] quer como manifestação de propaganda do esporte e da natação, quer do lado technico, cujos resultados sempre foram acima do esperado" (“A GAZETA"...,1932, p.9). O fim da prova tinha marcado um hiato na empolgação em relação às disputas no rio Tietê, tanto por parte dos atletas quanto do público.

Para pôr fim a esse vazio, o jornal decidiu patrocinar a segunda fase da prova de natação. O novo modelo seguiria um caráter mais popular, assim como já ocorria com a competição de pedestrianismo São Silvestre, também patrocinada pela $A$ Gazeta. Isso significou a adoção de medidas como inscrições gratuitas e retirada da exigência de competidores filiados à federação de esportes aquáticos (“A GAZETA”...,1932, p.9). Outra alteração foi a data: para não haver concorrência com a prova de pedestrianismo São Silvestre, realizada no último dia do ano, a Travessia foi marcada para a segunda quinzena de fevereiro, momento em que as cheias do rio ainda podiam ser aproveitadas.

Alguns dias depois, no mesmo jornal, o regulamento da prova foi divulgado. A ampliação no número de competidores, pretendida pelo periódico, foi assegurada pelo regulamento que previa que qualquer pessoa apta poderia se inscrever gratuitamente, desde que amadora e maior de 16 anos. O regulamento informava ainda que novas categorias de competição foram adicionadas, para além do "masculino" e "feminino"; agora, as classes "novíssimo", "novo" e "junior" seriam premiadas (A VI...1932, p.9). A especificidade da disputa passava a ser marcada por categorias, que competiriam entre si e aumentariam as chances dos concorrentes.

A expansão da possibilidade de inscrições começou a surtir efeito: no começo de fevereiro, 202 nadadores já haviam se candidatado, o que superava o número máximo de inscritos na primeira fase (FOI...1932, p.2). Tal sucesso provocava também uma necessidade de mudança na prova e seus regulamentos, e, sendo essa questão percebida pelo jornal, foram anunciadas "providências para não haver falha alguma na disputa" (DIA...1932, p.9). Em 24 de fevereiro, uma reunião entre os membros dos principais clubes náuticos da cidade e outros participantes interessados foi demandada pelo jornal, a fim de tratar "[...] assumptos de alto valor, para o completo exito da maior prova nautica do Brasil” (SÃO...1932 p.9).

Uma das alterações idealizada foi em relação à largada da prova. As saídas foram organizadas por páreos com aproximadamente cem atletas. A escolha dos atletas que comporiam cada turma seria feita pelos clubes aos quais eles eram filiados, e foi publicada de antemão no jornal. Apenas na categoria feminina a saída foi dada uma única vez, sendo a última delas. $\mathrm{Na}$ chegada, todos os nadadores seriam cronometrados, e no tempo final eram descontadas as diferenças da partida.

A prova teve 644 inscritos e 441 participantes que participaram da largada, sendo, dessa quantia, 52 atletas da classe feminina. A grande propaganda desempenhada pelo jornal fez com que o número de participantes e espectadores superasse sobremaneira as edições anteriores. A Gazeta chegou a anunciar mesmo que quarenta mil pessoas assistiram ao desenrolar da prova (QUARENTA...1932, p.2)

Para Vigarello (1995; 2002; 2018b) e Terret (2019), o esporte tornou-se, no século XX, 
um objeto universalmente visível, que é tanto mais poderoso quanto mais difundido. Nesse sentido, a imprensa escrita desempenhou um importante papel na difusão das práticas esportivas. Como exemplo podemos citar a importante competição ciclística Tour de France que foi criada em 1903 pelo grande jornal francês L'Auto, atual L'Équipe. (WEBER, 1988; VIGARELLO, 1995; 1997; 2018b; LESSA; MORAES E SILVA, 2017). Logo, a ampliação da divulgação da prova por parte do jornal $A$ Gazeta seguia essa lógica tendo objetivos bem definidos: aumentar a popularidade dos esportes aquáticos na cidade e a dimensão de seu arrebatamento.

A prova de 1933 contou com mais uma novidade em relação às regras: o sistema de chegada em funil. Nesse sistema, a partir do momento em que o nadador adentrasse essa estrutura, ele não mais poderia ser ultrapassado:

Nesse funil, que será feito no leito do rio, apenas caberá um nadador e o que estiver atraz não poderá passar á frente pois si isto fizer será desclassificado incontinenti.

A grande prova terminará na entrada principal do funil, onde sera anotado o tempo exacto de cada nadador e a sua classificação será feita na sahida do funil, com 100 metro de comprimento, pelos juizes anotadores. (IX...1935, p.11)

Nesse mesmo ano, houve uma mudança de data ocasionada pela confluência de provas da Federação Paulista de Natação ${ }^{10}$, e a Travessia foi realizada apenas em 26 de março, já depois do fim do verão. Esse fato ocasionou reclamações de alguns competidores que alegaram câimbras por conta da temperatura da água, como demonstra uma carta enviada ao jornal $A$ Gazeta por um dos competidores:

\begin{abstract}
A "Travessia de S. Paulo a Nado" não deverá ser realizada em mez de março. Vós que tão correctamente organizaste esta travessia deveis aceitar a minha sugestão. Podeis consultar os nadadores desistentes e podeis notar que a causa maior foram as caimbras (que a mim tambem me obrigaram a desistir) e isso unicamente por causa da temperatura da água que estava insuportável. [...]. Suggiro que a "travessia de São Paulo a Nado" seja feita entre 20 de dezembro e 10 de janeiro. (FALA...1933, p.7)
\end{abstract}

O mesmo ocorreu em 1939, quando, através de pedido da Federação de Natação, a competição foi transferida para o mês de abril, o que não agradou a todos os concorrentes (ENCERRAM-SE...1939). A época do ano era muito determinante para a realização das provas aquáticas no Tietê. Os meses de dezembro a fevereiro, com o verão e as cheias, eram os mais concorridos para as competições da Federação e outros torneios e travessias. A temperatura e o volume da água influenciavam de forma quase que decisiva no desempenho dos participantes.

10 Em 1932, após apelos relacionados à especificidade da natação em relação ao remo, uma nova federação voltada exclusivamente a este esporte foi criada, a Federação Paulista de Natação. A ideia da nova federação era promover melhorias ao esporte e divulgar os regulamentos internacionais (VAMOS..., 1931). 
As questões relativas à vazante do rio foram determinantes também na disputa de 1935. Semanas antes da realização da prova, esperava-se um bom resultado dos nadadores e, sobretudo, recordes quebrados, já que o rio continuava a subir com as chuvas que caiam sem cessar no verão paulistano:

O rio Tietê está subindo cada vez mais com as continuas chuvas que têm cahido. O leito do rio está com $1 \mathrm{~m} 940$ e si continuar assim até o dia da realização da prova - 24 do corrente - o recorde da grande competição 51'21"4/5 - irá cahir! No anno passado o nível das aguas do Tiete estava a 1 metro de altura e o resultado de Max Define foi de 53'32". Com maior altura e volume de agua o rio terá maior e mais forte correnteza e isso favorece de forma notável a actuação de todos os nadadores, levandoos em todo o percurso, até a chegada, sem esforço, melhorando muito o resultado technico (NUMEROSAS...1935, p.10)

O resultado da aliança entre técnicas cada vez mais apuradas e a benevolência da natureza não poderia ter sido outro: os recordes da prova foram quebrados, tanto na categoria feminina quanto na masculina. João Havelange e Max Delfine terminaram juntos a prova, com o tempo de 45'38'. Maria Lenk foi a primeira colocada do grupo feminino e $16^{\mathrm{a}}$ colocada geral, com o tempo de 47'45" (NOVO...1935, p.2).

É possível perceber que a vazão do rio foi, ao longo dos anos de competição, muito mais determinante na obtenção de melhores marcas do que a própria técnica dos nadadores, embora as equipes se preparassem de forma estratégica para a prova, repetindo o percurso, refazendo com velocidade as curvas e aproveitando a correnteza. Isso significa que, por mais que a tentativa fosse de dominar o rio e subjugá-lo às regras e quantificações presentes no esporte, ele ainda se sobressaia e era capaz de determinar, com sua natureza imprevisível, as melhores marcas obtidas pelos atletas.

Nenhuma outra grande mudança ocorreu na prova entre os anos de 1933 e 1944, ano em que a última competição foi disputada. Embora as transformações aqui narradas pareçam pequenas, elas foram de suma importância para a disputa da prova. O começo modesto, com poucos participantes, não instituía a necessidade de preocupação com a contagem do tempo dos concorrentes, já que poucos juízes seriam capazes de realizar a tarefa. $\mathrm{O}$ aumento exponencial no número de concorrentes fez com que novas regras precisassem se impor, a fim de controlar e regulamentar a disputa.

Pouco a pouco novos cargos de arbitragem passaram a existir, como os juízes de percurso, de chegada, de saída, árbitro central, cronometristas. Botes de percurso foram inseridos, para os cuidados com os desistentes. As saídas passaram a ser organizadas em blocos de competidores, e as chegadas se adequaram ao modelo de funil. Todas essas pequenas alterações serviram para tornar a prova cada vez mais regulamentada e adaptada as lógicas do esporte moderno.

A questão dos recordes, embora de vital importância para um esporte como a natação, não galgou êxito na travessia. Primeiro porque a distância anunciada no percurso era distinta, apesar de os limites de chegada e saída fossem os mesmos, e só foi instituída nos 5500 metros a partir de 1934. Em segundo lugar, a vazão do rio era muito mais determinante do que o treinamento dos atletas. Nos anos em que o rio esteve mais cheio, como 1935 e 1940, os recordes da prova foram quebrados, ainda que os mesmos nadadores tenham feito a prova em outros anos e alcançado resultados muito inferiores. 
Uma análise mais minuciosa da prova mostra que, de fato, a Travessia se associava cada vez mais às práticas esportivas, e se distanciava dos primeiros desafios realizados nos rios. As regras e delimitações tornaram-se, ao longo do tempo, bastante claras, e a associação dos jornais com as Federações aquáticas dava um ar muito mais importante ao certame.

\section{Considerações finais}

Acidade de São Paulo, fremente nas primeiras décadas do século XX, sofreu intervenções diversas em seus costumes e modos de vida. Uma dessas mudanças foi a forma de realizar exercícios e outras atividades de divertimento: estava em marcha a imposição de uma cultura física à cidade, que tinha pretensões bastante definidas, assinaladas por higienistas, jornalistas, professores e médicos. Dentre os incentivadores de novas práticas, localizavam-se os clubes de regatas da cidade, bastante dispostos a difundir os modos adequados de "ser um esportista".

Essa cultura física presente na cidade tornava-se cada vez mais esportivizada. Os desafios e outras práticas realizadas nos rios e pelos clubes analisados ganhavam características como regulamentação, especificidade, cronometragem do tempo, marcação de recordes. Pouco a pouco os torneios, campeonatos, disputas, matches e travessias ganhavam elementos que os aproximavam de práticas internacionalmente instituídas de natação e remo.

A prova da Travessia de São Paulo a Nado refletiu, com o passar de suas edições, essa tendência à esportivização. A preocupação com a regulamentação da prova foi crescente. Com isso, mais juízes foram inseridos para o controle do evento, e cronometristas adicionados ao final do percurso. Também foram estabelecidas novas diretrizes para as saídas e chegadas, tornando-as mais facilmente controláveis e diminuindo o risco de fraudes. O sistema de identificação dos atletas foi utilizado já nas primeiras edições, para melhorar o reconhecimento de cada competidor ao longo da prova.

Ao retomarmos Guttmann (2004) e Vigarello (1995; 2002; 2008; 2018b) e suas caracterizações do esporte moderno, podemos inferir que, de fato, a travessia se aproximava muito mais dos esportes do que dos desafios que a precederam. A tentativa de igualar a condição de disputa dos concorrentes a partir de novas regras de saída e chegada; a crescente importância das regras na disputa; a notável necessidade de quantificação dos tempos obtidos pelos nadadores são exemplos das características esportivas que a prova ganhou ao longo do tempo.

A busca pelos recordes, outra notável propriedade dos esportes apontada por Guttmann (2004) e Vigarello (1995; 2002; 2008; 2018b), sofria revezes por um único motivo: a água dos rios. Nos rios é difícil medir, quantificar, controlar a técnica das braçadas, organizar a linha de chegada, controlar a velocidade das águas, realizar treinamentos específicos. Os recordes elementos primordiais na realização dos esportes de marca - dependiam não só do esforço do participante, mas principalmente da correnteza e do estado do rio na data selecionada.

Podemos avaliar, ainda, que a impossibilidade da quebra de recordes e os "excessos" da natureza dos rios foram fatores que, associados ao crescimento das cidades, à transformação das margens do Tietê e à poluição, acabaram afastando as práticas esportivas desse espaço. Foi ainda possível perceber, na análise das fontes, que paulatinamente a prova foi sendo preterida pelas Federações, que optavam por dar lugar, quando na mesma data, a competições de cunho 
"oficial" realizadas em outros ambientes.

A construção das piscinas nos clubes aqui citados ${ }^{11}$ foi, certamente, um fator relevante para a diminuição de competições no rio. Machemehl (2011), ao estudar a cidade francesa de Rouen, analisou que as piscinas construídas pelos clubes ajudaram a sociedade a darem as costas ao rio. Em São Paulo, essa máxima também foi verdadeira, e os anos 1940 foram marcados como o último reduto das competições aquáticas realizadas nas águas do Tietê.

\section{Referências}

"A GAZETA" vae fazer resurgir a tradicional prova "travessia de s. paulo a nado" que foi e será a maior competição brasileira de natação. A Gazeta, São Paulo, n. 7779, p.9, 09 jan. 1932.

A “TRAVESSIA de S. Paulo a nado”. Correio paulistano. São Paulo, n. $\quad$ 22062, p.6, 28 dez. 1924

A II. ${ }^{a}$ travessia de S. Paulo a nado. A Gazeta. São Paulo, n.5954, p.5, 10 dez. 1925.

A III travessia de S. Paulo a nado. Correio paulistano. São Paulo, n.22764, 05 dez. 1926.

A IV travessia de S. Paulo a nado. Correio paulistano. São Paulo, n.23107, p. 8, 07 dez. 1927.

A TRAVESSIA de São Paulo a nado. A Gazeta. São Paulo, n.5599, p. 4, 23 set. 1924a

A TRAVESSIA de São Paulo a nado. Correio paulistano. São Paulo, n. 23437, p. 9, 29 dez. 1928.

A TRAVESSIA de São Paulo a nado - abertura das inscripções. A Gazeta. São Paulo, n.5643, p.3, 19 nov. 1924b.

A VI “Travessia de São Paulo a nado”. A Gazeta. São Paulo, n.7782, p.9, 22 jan. 1932.

BOURDIEU, Pierre. Como é possível ser esportivo? In. Questões de sociologia. Lisboa: Fim de século, 2003.

CLUB Esperia. Correio Paulistano, São Paulo, n. 14816, p. 3, 9 nov. 1904.

CRUZ, Heloisa de Faria. São Paulo em papel e tinta: periodismo e vida urbana - 1890-1915. São Paulo, SP: Imprensa Oficial, 2000.

DEVIDE, Fabiano Pries; VOTRE, Sebastião Josué. Primórdios da natação competitiva feminina: do" páreo elegância" aos Jogos Olímpicos de Los Angeles. Revista Brasileira de Ciências do Esporte, v. 34, n. 1, p. 217 -

11 O Clube de Regatas Tietê construiu sua piscina em 1932 e o Clube Esperia em 1933 (NICOLINI, 2001) 
$233,2012$.

DIA 28 de fevereiro, será disputada sob o patricinio da "Gazeta", a "VI Travessia de S. Paulo a nado". A Gazeta. São Paulo, n.7790, p.9, 22 jan. 1932.

DISPOSIÇÕES do árbitro. Correio paulistano. São Paulo, n.23431, p.8, 21 dez. 1928.

E A TRAVESSIA de São Paulo em que ficou?.... A Gazeta. São Paulo, n.5515, p.4, 27 mai. 1924.

ELIAS, Norbert; DUNNING, Eric. A busca pela excitação. Lisboa: Difel, 1992

ENCERRAM-SE hoje as inscrições de clubes e concorrentes á XIII Travessia de São Paulo a Nado.A Gazeta Caderno esportivo. São Paulo, p. 11, 10 abr. 1939.

FALA um desistente... . A Gazeta. São Paulo, n.8165, p.7, 30 jan. 1933.

FOI superado o recorde das inscrições da "VI Travessia de S. Paulo a nado. A Gazeta - Caderno esportivo. São Paulo, p.2, 15 fev. 1932.

FURTADO, Heitor Luiz., Quitzau, Evelise Amgarten, Moraes e Silva, Marcelo. Blumenau e seus imigrantes: apontamentos acerca da emergência de uma cultura física (1850-1899). Movimento, v. 24, n. 2, p. 665-676, 2018.

GÓIS JUNIOR, Edivaldo. A institucionalização da educação física na imprensa: a construção da escola superior de educação physica de s. Paulo na década de 1930. Movimento, p. 701-714, jun. 2017. ISSN 1982-8918. Disponível em: <https://seer.ufrgs.br/Movimento/article/view/69223>. Acesso em: 29 fev. 2020. doi:https://doi. org/10.22456/1982-8918.69223.

GOUVEIA, Isabel Cristina Moroz-Caccia. A cidade de São Paulo e seus rios: uma história repleta de paradoxos. Confins. Revue franco-brésilienne de géographie, n. 27, 2016.

GUTTMANN, Allen. From ritual to record. New York: Columbia University Press, 2004.

IV travessia de São Paulo a nado. Correio Paulistano, São Paulo, n.23114, p. 8, 15 dez. 1927.

IX Travessia de São Paulo a Nado. A Gazeta - Caderno esportivo. São Paulo, p.11, 18 fev. 1935.

JAYO, Martin. Trajetórias e ideias de Cásper Líbero (monografia). Revista PJ:Br. Jornalismo brasileiro. São Paulo, ECA-USP, Edição 1, primeiro semestre, 2003.

JORGE, Janes. Tietê, o rio que a cidade perdeu: o Tietê em São Paulo 1890-1940. Alameda, 2006. 
JORGE, Janes. São Paulo das enchentes, 1890-1940. Histórica, v. 47, p. 1-7, 2011.

KIRK, David. Physical Culture, Physical Education and Relational Analysis. Sport, Education and Society, v.4, n.1, p.63-73,1999.

KIRK, David. Los futuros de la Educación Física: la importancia de la cultura física y de la «idea de la idea» de Educación Física. In: AA. VV. Actas V Congreso Asociación Española de Ciencias del Deporte. León: Universidad de León. (CD-R), 2008.

LESSA, Priscila Requião; MORAES E SILVA, Marcelo. O ciclismo de estrada e a construção de uma cultura nacionalista: um olhar sobre o Tour de France. Movimento, v. 23, n. 1, p. 407-418, 2017.

LOUDCHER, Jean-François. À propos de la traduction française du livre de Allen Guttmann, From Ritual to Record: the Nature of Modern Sports. Staps, n. 2, p. 39-51, 2008.

MACHEMEHL, Charly. La Seine et les loisirs sportifs: le site rouennais dans l'entre-deux-guerres. VertigO-la revue électronique en sciences de l'environnement, n. Hors-série 10, 2011.

MONTENEGRO, Nara Romero; SOARES, Carmen Lúcia. Cultura physica e vida ao ar livre: a reinvenção do litoral de Fortaleza (1920-1940). Movimento, v. 25, p. 25092, 2019.

MORAES E SILVA, Marcelo. Novos modos de olhar outras maneiras de se comportar:

a emergência do dispositivo esportivo da cidade de Curitiba (1899-1918). 2011. 227f. Tese (Doutorado) Faculdade de Educação, Universidade Estadual de Campinas, 2011.

MORAES E SILVA, Marcelo. Comportamentos urbanos e Esportes: contribuições para a esportivização do Turfe e da Pelota Basca em Curitiba (1899-1905). Licere (Centro de Estudos de Lazer e Recreação. Online), v. 18, p. 86-115, 2015.

MORAES E SILVA, Marcelo; QUITZAU, Evelise Amgarten; SOARES, Carmen Lucia. Práticas educativas e de divertimento junto à natureza: a cultura física em Curitiba (1886-1914). Educação e pesquisa, v. 44, p. 178293, 2018 .

MORAES E SILVA, Marcelo; QUITZAU, Evelise Amgarten. A cultura física na cidade de Curitiba: a emergência de uma pedagogia corporal (1899-1909). Revista de Ciencias Sociales - Arturo Prat, v. 41, p. 275-296, 2018.

NATAÇÃO. Correio Paulistano, São Paulo, n. 12446, p. 2, 27 fev. 1898.

NICOLINI, Henrique. Tietê: o rio do esporte. São Paulo, SP: Phorte, 2001. 
NOVO recorde da prova: 45"38" de Havellange e Delfine. A Gazeta - Caderno esportivo. São Paulo, p.2, 25 fev. 1935.

NUMEROSAS inscripções para a IX Travessia de S. Paulo a nado. A Gazeta - Caderno esportivo. São Paulo, p.10, 11 fev. 1935.

O QUE É necessário para poder ser um esportista?. Tietê - Revista dos Tietanos, São Paulo, ano 1, n. 6, p. 7, mar. 1936.

O VERDADEIRO esportista. Esperia - Revista Mensal do Club Esperia, São Paulo, ano 4, n. 42, p. 6, abr. 1932.

ORIENTAÇÃO inteligente e patriótica. Tietê - Orgão oficial do C.R. Tietê, São Paulo, ano 1, n. 3, p. 1, mar. 1940.

PELAYO, Patrick. De l'art de nager à la science de la natation. La revue pour l'histoire du CNRS, n. 26, p. $18-23,2010$.

QUARENTA mil pessoas assistiram hontem ao desenrolar da "VI Travessia de São Paulo a nado". A Gazeta Caderno esportivo. São Paulo, p.2, 29 fev. 1932.

RAUCH, André. Les vacances et la nature revisitée. In : CORBIN, Alain. L'avènement des loisirs (1850-1960). Paris, Aubier, p.108-153, 1995.

ROWING. Correio Paulistano, São Paulo, n. 15021, p. 2, 5 jun. 1905.

SANT'ANNA, Denise Bernuzzi. Cidade das águas: usos de rios, córregos, bicas e chafarizes em São Paulo (1822-1901). São Paulo, SP: SENAC, 2007.

SÃO convidados. A Gazeta. São Paulo, n.7817, p.9, 24 fev. 1932.

SCHARAGRODSKY, Pablo Ariel. Palabras preliminares. In: SCHARAGRODSKY, Pablo Ariel. Miradas médicas sobre la cultura física en Argentina (1880-1970). Buenos Aires: Prometeo, 2014.

SCHARAGRODSKY, Pablo. ¿Cruzando fronteras? La prensa y el primer cruce a nado del Río de la Plata, Uruguay-Argentina, 1923. Claves. Revista de Historia, v. 5, n. 8

2019, p. 211-233.

SEVCENKO, Nicolau. Orfeu extatico na metropole: São Paulo, sociedade e cultura nos frementes anos 20. São 
Paulo, SP: Companhia das Letras, 2000.

TERRET, Thierry. Naissance et diffusion de la natation sportive. Paris: Editions L'Harmattan, 1994.

TERRET, Tierry. Professional swimming in England before the rise of Amateurism, 1837-75. The International Journal of the History of Sport, v. 12, n. 1, 1995, p. 18-32. doi:10.1080/09523369508713881

TERRET, Thierry. L'institution et le nageur: histoire de la Fédération française de natation (1919-1939). Lyon : Presses universitaires de Lyon, 1998.

TERRET, Thierry. Histoire du Sport. Paris: Presses Universitaires de France, 2019.

TOLEDO, Luiz Henrique de. A cidade e o jornal: a Gazeta Esportiva e os sentidos da modernidade na São Paulo da primeira metade do século XX. In: HOLLANDA, Bernardo Borges Buarque; MELO, Victor Andrade et. al. (org.). O esporte na imprensa e a imprensa esportiva no Brasil. Rio de Janeiro, RJ: 7Letras, 2012.

UMA IMPORTANTE competição nautica. A Gazeta. São Paulo, n.5595, p.4, 18 set. 1924.

THALASSA, Ângela. Correio Paulistano: o primeiro diário de São Paulo e a cobertura da Semana de Arte Moderna. 2007. 158 f. Dissertação (Mestrado) - Programa de Pós-graduação em Comunicação Social, PUC, São Paulo, 2007.

VAMOS fundar a Federação Paulista de Natação? A Gazeta. São Paulo, n. 7476, p. 11, 13 jan 1931.

VIGARELLO, Georges. Le temps du sport. In : CORBIN, Alain. L'avènement des loisirs (1850-1960). Paris, Aubier, p.251-290, 1995.

VIGARELLO, Georges. Le Tour de France. In: NORA, Pierre. (Ed.). Les Lieux de mémoire, Paris: Gallimard, v. 2, p. 885-925, 1997.

VIGARELLO, Georges. Du jeu ancien au show sportif: la naissance d'un mythe. Paris : Éditions Seuil, 2002.

VIGARELLO, Georges. Le corps redressé: Histoire d’un pouvoir pédagogique. Paris: Félin, 2018a.

VIGARELLO, Georges. Histoire. Paris: Le Pommier, $2018 \mathrm{~b}$.

VIGARELlO, Georges. Le Propre et le Sale: L'hygiène du corps depuis le Moyen Age. Paris : Le Seuil, 2019.

VIGARELLO, Georges; Holt, Richard. El cuerpo cultivado: gimnastas y deportistas en el siglo XX. In: Corbin, A; Courtine, J. J.; Vigarello, G. Historia del cuerpo: De la revolución francesa a la Gran Guerra. Madrid: Taurus, 
p. 295-354, 2005.

VIGARELLO, Georges. "Treinar". In: VIGARELLO, Georges; CORBIN, Alain; COURTINE Jean-Jacques. História do Corpo: as mutações do olhar - o século XX. São Paulo; Vozes, volume 2. pp. 197-252, 2008.

VIVIER, Christian. La sociabilité canotière: la société nautique de Besançon. Paris: Editions L'Harmattan, 1999.

VIVIER, Christian, Pleasures of Senses: the History of the Disappearance of La Nautique de Besançon, 18651930, The International Journal of the History of Sport, 15, n², pp. 176-185, 1998.

WEBER, Eugen Joseph J. França fin-de-siècle. São Paulo: Companhia das Letras, 1988.

RECEBIDO EM:05/03/2020

APROVADO EM: 09/04/2020 